\title{
ROLE OF ENZYMES IN THE REMEDIATION OF POLLUTED ENVIRONMENTS
}

\author{
M.A. Rao, R. Scelza, R. Scotti and L. Gianfreda* \\ Dipartimento di Scienze del Suolo, della Pianta, dell'Ambiente e delle Produzioni Animali, \\ Università di Napoli Federico II, Via Università 100, 80055 Portici, Napoli, Italy. \\ *Corresponding author: liliana.gianfreda@unina.it
}

\begin{abstract}
Environmental pollution is growing more and more due to the indiscriminate and frequently deliberate release of hazardous, harmful substances. Research efforts have been devoted to develop new, low-cost, low-technology, eco-friendly treatments capable of reducing and even eliminating pollution in the atmosphere, the hydrosphere and soil environments. Among biological agents, enzymes have a great potentiality to effectively transform and detoxify polluting substances because they have been recognized to be able to transform pollutants at a detectable rate and are potentially suitable to restore polluted environments. This brief review will examine some classes of pollutants and enzymes capable of transforming them effectively into innocuous products. Particular attention will be devoted to pollutants with a high polluting potential such as polyphenols, nitriles, PAHs, cyanides and heavy metals. The enzymatic processes developed and implemented in some of these detoxification treatments will be examined in details. The main advantages as well as the main drawbacks that are still present in the extensive application of enzymes in the in situ restoration of polluted environments will be discussed.
\end{abstract}

Keywords: Pollutants, enzymes, environmental pollution, bioremediation.

\section{INTRODUCTION}

Several substances with high polluting potential are present in the environment and affect soil, sediments, water, air, microbial organisms, plants, animals, and humans. They may be distributed in one or all environmental compartments. A list of the most common and widespread pollutants is shown in Figure 1. Polluting substances are very often present not only as mixtures of different organic compounds but also of organic and inorganic ones. The origins and sources of pollution are different: industrial activities such as mining and metal processing, petrochemical and industrial complexes, industry effluents, chemical weapons production, pulp and paper industries, dye industries and industrial manufacturing; and anthropogenic activities such as traffic, agricultural practices, and others. Pollutants may affect the health of humans, animals and environments for several causes. They may inhibit respiration. They may provoke a reduced reproduction of fish-eating birds as well as contribute to the birth of premature babies or children with genetic defects such as downs syndrome, anencephaly, 
POLLUTANTS

Organic
Pesticides
N and P derivatives
PAHs
BTEX
PCPs
NAPL
Plastics, Biopolymers
Dyes
Phenols, Chlorophenols
Choroanilines
Bleach plant effluents
Nitrocompounds

\section{Inorganic}

Arsenic

Cadmium

Chromium

Copper

Lead

Cyanide

\author{
Air-Pollutants \\ Particulates \\ Greenhouse gases \\ Smog forming compounds
}

Figure 1. Organic, inorganic and air-pollutants possibly encountered in the environment.

and spina bifida. They may destruct reproduction in humans and animals, may have carcinogen and teratogenic effects on humans, and may give rise to arsenicosis and related damages.

In 2007, the Blacksmith Institute of New York launched the second annual review of the most 2007 World's Worst Polluted Places - The Dirty Thirty Summary Matrix - which also includes the top ten polluted sites. Almost all regions of the world have different and widespread types of pollutants and pollutant sources, i.e. Africa, China, Eastern Europe, Central and South Asia, Latin America and others (Blacksmith Institute, 2007).

Most of these areas are located in poor countries where pollution continues to be a major cause of death, illness and long-term damage. Also Western Europe is not free from environmental pollution. Table 1 reports an inventory of polluted sites in Western Europe dated in 2008 (Gianfreda and Greco unpublished results). More than 200,000 polluted sites have been identified in developed countries such as Germany. In the Netherlands, 115,000 polluted sites have been estimated, though most of them have not been identified yet. These numbers give an idea of the enormous magnitude of pollution in the environment. And it could be said that a large part or even the entire earth is polluted.

As the increase of contaminated sites poses a major environmental and human health problem, it appears mandatory to decontaminate the environment and to implement efficient decontamination strategies. The main goals of decontamination should be recovery of soil health and fertility, detoxification of ground-water, reutilization of wastewater (mainly in countries with severe water deficiency), removal of negative effects on human and animal health, and production of healthy air. Therefore, a growing interest is being devoted to the search of effective remediation technologies for partial or total recovery of polluted sites. The nature of the contaminant sources and the co-occurrence of organic and inorganic compounds often make their remediation problematic.

Several methodologies have been applied for the remediation of polluted systems and many of them, when 
Table 1. Inventory of polluted sites in Western Europe.

\begin{tabular}{lcc}
\hline Country & \multicolumn{2}{c}{ Potentially polluted sites } \\
& Identified & $\begin{array}{c}\text { Estimated } \\
\text { Total }\end{array}$ \\
\hline Austria & 28,000 & 80,000 \\
Belgium & 7,728 & 14,000 \\
Denmark & 37,000 & 40,000 \\
Finland & 10,396 & 25,000 \\
France & - & 750,000 \\
Germany & $\mathbf{2 0 2 , 8 8 0}$ & 240,000 \\
Iceland & - & 350 \\
Ireland & - & 2,000 \\
Italy & 8,873 & - \\
Luxemburg & 616 & - \\
Netherlands & - & $\mathbf{1 1 5 , 0 0 0}$ \\
Norway & 2,121 & - \\
Spain & 4,902 & - \\
Sweden & 7,000 & - \\
Switzerland & 35,000 & 50,000 \\
UK & - & 100,000 \\
\hline
\end{tabular}

implemented in the target sites, have led to successful results. Two basic strategies have been utilized: engineering and biological ones (Bollag and Bollag, 1995). Engineering strategies are basically founded on physical and chemical methods, whereas biological strategies require the involvement of biological agents (Gianfreda and Rao, 2008). Composting, land farming, bioreactors, bioremediation, and phytoremediation are the main biological methods applicable to soil and groundwater. Land farming is not suitable for the latter. Regardless the adopted method, the decontamination of polluted sites may be carried out by in-situ (if soils and water are treated directly on site) or ex-situ (if they are excavated, transported to another site and, then treated) treatments. In situ techniques are usually less expensive and involve less physical treatments, whereas ex situ treatments require higher costs and an increased environmental disturbance.

Bioremediation and phytoremediation appear now as appealing technologies being based on the use of living organisms, microorganisms, plants, and their enzymatic set.

\section{ENZYMES AS DECONTAMINATING AGENTS}

The use of enzymatic proteins may represent a good alternative for overcoming most disadvantages related to the use of microorganisms (Nannipieri and Bollag, 1991; Karam and Nicell, 1997; Nicell, 2001; Gianfreda and Bollag, 2002, Gianfreda and Rao, 2004).

Enzymes have several beneficial characteristics. They are the main effectors of all the transformations occurring in the biota. They are catalysts with either narrow (chemo-, region- and stereo-selectivity) or broad specificity and, therefore, they can be applied to a large range of different compounds in mixture, as well. They may produce extensive transformations of structural and toxicological properties of contaminants, and even their complete conversion into innocuous inorganic end products. They may perform processes for which no efficient chemical transformations have been devised.

Moreover, enzymes may present advantages over traditional technologies, and also over microbial remediation. Indeed, enzymes are not inhibited by inhibitors of microbial metabolism. They can be used under extreme conditions limiting microbial activity. They are effective at low pollutant concentrations and are active in the presence of microbial predators or antagonists. They act against a given substrate (microorganisms may 
prefer more easily degradable compounds than the pollutant), and are more mobile than microorganisms because of their smaller size (Gianfreda and Bollag, 2002). All these characteristics render enzymes eco-friendly catalysts as well as enzymatic techniques environmentally friendly processes. These latter may have the capability of remediation of many compounds that are unfriendly to the environment by the present ecological standards of our societies. As claimed by Alcade et al., (2006), biocatalysis by enzymes (very often known as white biotechnology) "fully participates in the "green chemistry" concept introduced in the 90 s by Sheldon and van Rantwijk, (2004), and its effect on sustainability is now established beyond question".

Enzymes may act intracellularly, i.e. in the presence of or inside their originating cells; extracellularly, i.e. both in the presence or absence of their originating cells; free, i.e. soluble in solution and the catalysis will be homogenous; or immobilized, i.e. linked through different links to a solid matrix and the catalysis will be heterogeneous (Gianfreda and Rao, 2004).

Recently, very interesting examples of structures and methods for immobilization of biomolecules, including enzymes, were illustrated by Rodríguez Couto and Toca Herrera (2006) with specific reference to laccase, an enzyme very often used in decontamination of pollutants (Gianfreda et al., 1999). Both 2D and 3D supramacromolecular structures can be used to immobilize biomolecules or to build microreactors (Figure 2). In the first case, polyelectrolyte multilayer, micropatterning and self-assembled monolayers (SAMs) appear to be suitable to the scope (Figure 2a), while hollow polyelectrolyte shells or colloidal particles covered by polyelectrolytes (and phospholipids) can host proteins inside and/or other types of functional molecules, permitting the diffusion of molecules through the shell wall (Figure 2b).

The most representative enzymatic classes in the remediation of polluted environments are: hydrolases, dehalogenases, transferases and oxidoreductases. Their main producers are bacteria, fungi, mainly white-rot fungi, plants and microbe-plant associations. For many of these enzymes the transformation of different xenobiotic substances has been tested mainly under laboratory conditions. Reagents and activity assay conditions are available for many of these enzymes, and they are described in detail to allow their easy detection and application (Whiteley and Lee, 2006).

Examples of hydrolases are phosphotriesterases, amidases, proteases, carbohydrases (cellulases and amylases), depolymerase. Mono- or di-oxygenases, reductases, dehalogenases, cytochrome P450 monoxygenases, phenoloxidases (laccases, tyrosinases) and peroxidases (lignin and manganese peroxidases) are the main classes of oxidoreductases.

The breakdown of esteric, amidic and peptidic bonds by esterases, amidases and proteases may lead to products with little or no toxicity. For instance, bacterial hydrolases such as carbamate or parathion hydrolases from Achromobacter, Pseudomonas, Flavobacterium, Nocardia, and Bacillus cereus have been successfully used in the transformation of pollutants such as carbofuran and carbaryl or parathion, diazinon and coumaphos (Coppella et al., 1990; Mulbry, and Eaton, 1991; Sutherland et al., 2002). Similarly, carbohydrases, depolymerases, proteases and phosphatases, produced by several bacteria and fungi, can be suitable for the transformation of insoluble materials such as carbohydrates, plastics and proteins (van Wyk, 1999, Nakamura et al., 2001; Singh, 2002).

Sornyotha et al. (2010) showed that the combination of xylanase and cellulose 

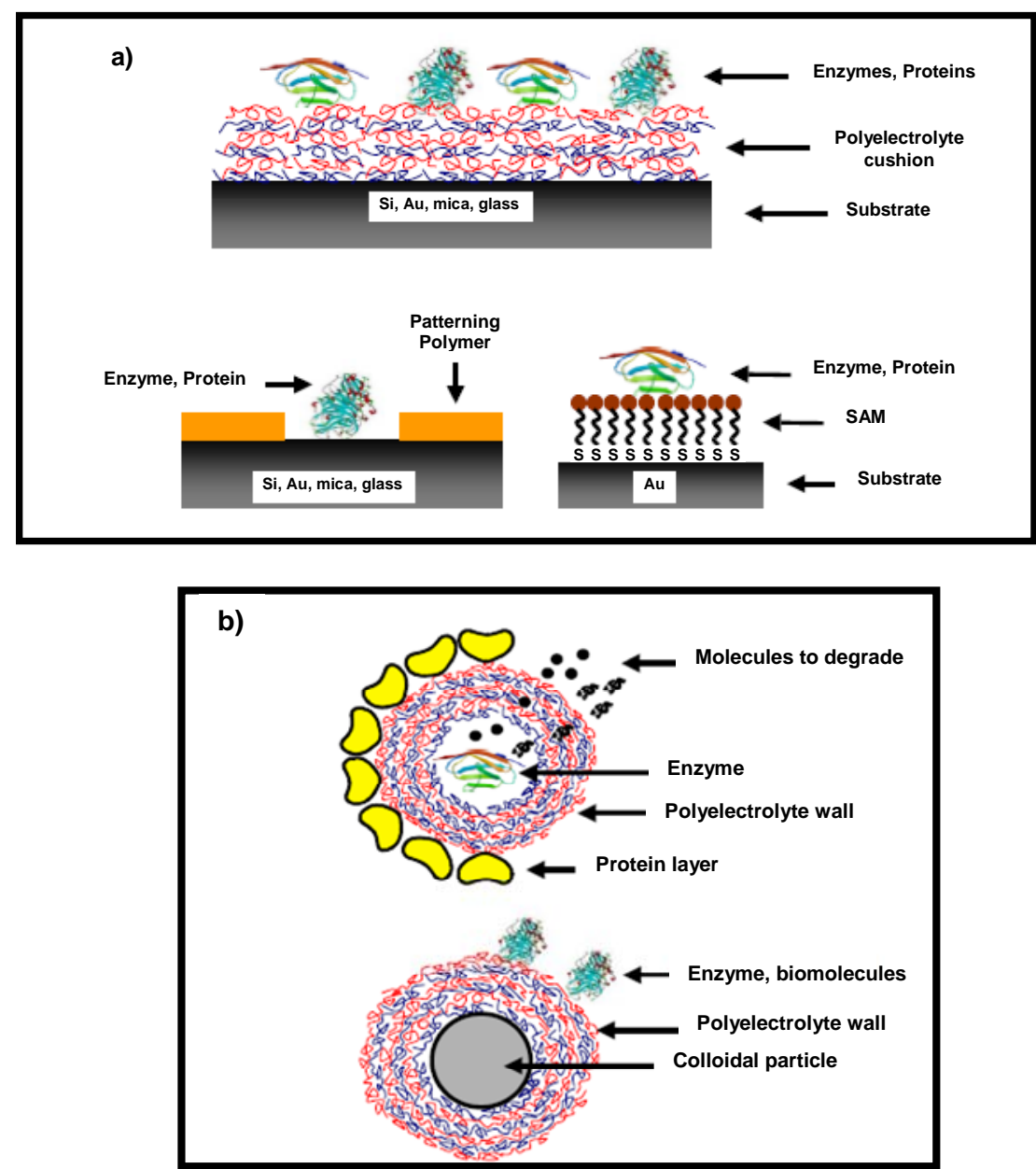

Figure 2. Supramacromolecular structures usable to immobilize biomolecules. a) $2 \mathrm{D}$ and b) 3D structures. For details see the text (From Rodríguez Couco and Herrera, 2006).

(two hydrolases acting as plant cell walldegrading enzymes) exerted a synergistic action on the removal of linamarin (a cyanogenic glycoside found in the leaves and roots of plants such as cassava, lime beans, and flax) from cell walls of cassava roots, a high-cyanogen variety, and on the release of linamarase. Linamarin liberation from parenchyma was enhanced by $90 \%$ with the combined enzyme treatment. In addition, when the combined enzymes were applied for detoxification during cassava starch production, a low-cyanideproduct was obtained with a decreased linamarin concentration (96\%) compared to the non-enzyme treated tissues. The author concluded that this method is more effective than the traditional detoxification method of adding linamarase directly and/or the treatment with some microorganisms. Moreover, this method could be used in the low-cyanide-cassava 
starch production and is suitable for detoxification of cassava products during processing.

An interesting role is played by a class of enzymes involved in the transformation of nitrile compounds (Banerjee et al., 2002; Singh et al., 2006). Nitrile is any organic compound which has a $-\mathrm{C} \equiv \mathrm{N}$ functional group. The $-\mathrm{C} \equiv \mathrm{N}$ functional group is called a nitrile group in which the carbon atom and the nitrogen atom are triple bonded together. The prefix cyano is used in chemical nomenclature to indicate the presence of a nitrile group in a molecule. A cyanide ion is a negative ion with the formula $\mathrm{CN}^{-}$. The $-\mathrm{CN}$ group is sometimes, less properly, referred to as a cyanide group or cyano group, and compounds with it are sometimes referred to as cyanides.

Many cyanide-containing compounds are highly toxic and deadly poisonous while some nitriles (which do not release cyanide ions) may have low toxicities. Nitrile compounds are synthesized by plants, fungi, bacteria, algae, insects and sponges.

There are two different enzymatic pathways for the degradation of nitrile compounds (Figure 3). One is a two step degradation involving nitrile hydratase and amidase via an amide as an intermediate. The other is the direct hydrolysis of nitriles to the corresponding acids and ammonia, catalyzed by nitrilase.

Nitrilases (EC 3.5.5.1) constitute branch 1 of the nitrilase superfamily, which comprises enzymes acting on nonpeptide $\mathrm{C} \backslash \mathrm{N}$ bonds. They are produced by both bacteria, such as Nocardia sp. and Rhodococcus sp., and fungi, as Fusarium solani or Aspergillus niger. Some of the nitrilases are capable of hydrolyzing nitriles stereospecifically. While much information is available on the structure and function of bacterial nitrilases (Banerjee et al., 2002; Singh et al., 2006), a lesser amount of findings is available for nitrilases from filamentous fungi.

Martínková et al. (2009) reviewed the current knowledge of these enzymes by examining findings on enzyme screening, production, purification and immobilization and prospective applications in the field of biocatalysis. In particular, they investigated the potentiality of fungal nitrilase and compared their performance with some from bacterial origins. Their studies established that the nitrilases of filamentous fungi have high relative activities toward (hetero) aromatic nitriles, and accept a wide range of aliphatic and alicyclic nitriles.

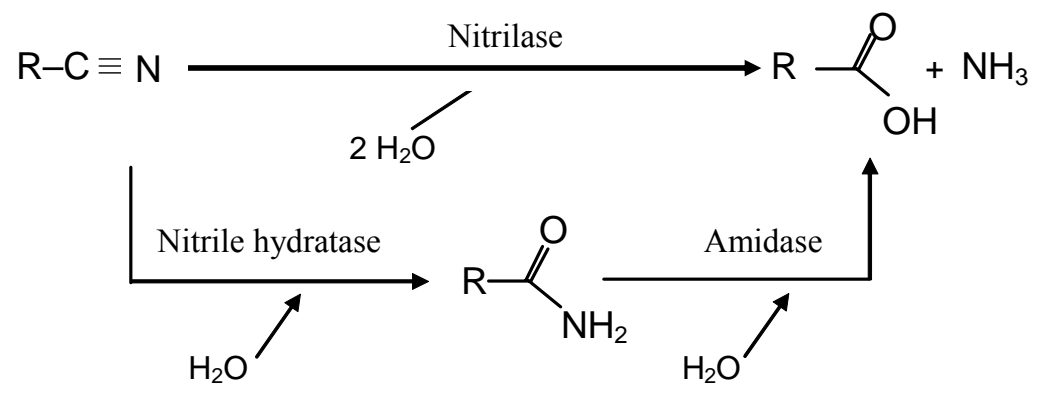

Figure 3. Enzymatic pathways for hydrolysis of nitriles. 
One of the benefits of fungal nitrilases is their high specific activity toward substances such as benzonitrile and analogues, 3- and 4-cyanopyridine and also some medium chain length aliphatic nitriles, considered their preferential substrates. For instance, A. niger nitrilase was able to transform a large range of different substrates at high rate as compared with bacterial nitrilase.

The biotechnological impact of nitrilases lies in their potential to accept a wide range of aliphatic and aclicyclic nitriles; to hydrolyze nitriles under mild conditions, with excellent regio- and enantioselectivities in some cases; to exhibit high activity, stability and thermostability. This makes these enzymes good candidates for biodegraders of nitrile contaminants.

Hydrogen cyanide $(\mathrm{HCN})$ is a major environmental pollutant of the chemical and metallurgical industries. It is produced on large scale worldwide to satisfy major industrial countries needs. Cyanide is extremely toxic to aerobic forms of life since it inhibits respiration by strongly binding to cytochrome oxidase (Solomonson, 1981).

Although extremely toxic, cyanide can enzymatically be converted to the less toxic thiocyanate by rhodaneses (thiosulfate:cyanide sulfurtransferases, EC 2.8.1.1), highly conserved and widespread enzymes now considered as one of the mechanisms evolved for cyanide detoxification (Raybuck, 1992).

A genetic system was engineered to express high levels of recombinant Pseudomonas aeruginosa rhodanese (rRhdA) in E. coli, and this organism was used to test the role of r-RhdA in cyanide detoxification (Cipollone et al., 2006). Active r-RhdA was obtained over a 4-h period, and the enzyme distributed between the cytoplasm (95\%) and the periplasm $(5 \%)$, as it was assessed by Western blot analyses and enzymatic assays. The accessibility of thiosulfate to $r$-RhdA limited the sulfur transfer reaction in the cellular system, but permeabilization of the bacterial membrane increased the cyanide conversion into thiocyanate. Overall results indicated that engineered $E$. coli was able to perform cyanide detoxification even under laboratory conditions, and suggested that microbial rhodaneses may contribute to cyanide transformation in natural environments (Cipollone et al., 2006).

An important group of enzymes is constituted by oxidative enzymes (Gianfreda et al., 1999; Durán and Esposito, 2000; Torres et al., 2003; Gianfreda and Rao, 2004; Gianfreda et al., 2006; Rodríguez Couto and Toca Herrera, 2006). They have a predominant role in the environment being involved in several processes including the detoxification of polluted environments (Figure 4). Indeed, they are involved in the formation of humus material in soil, in the exchanges between plants and soil through degradation and synthetic mechanisms. Moreover, they can be involved in the reactions between humus constituents and xenobiotic molecules and form bound residues in water systems and humus materials in soil (Figure 4a).

Their importance in the detoxification of polluted environments relies on their capability to catalyze the polymerization of toxic compounds alone or, by crossreaction, with other phenolics or with cosubstrates with toxic and harmless characteristics; and generate polymeric products (dimers, trimers, hybrid oligomers), which will very likely accumulate in soil and/or in water systems (Figure 4b).

The main producers of oxidative enzymes of significance to the remediation of polluted environments are white-rot fungi (Bumpous, 1993; Reddy, 1995; Pointing, 2001; Asgher et al., 2008; 
a)

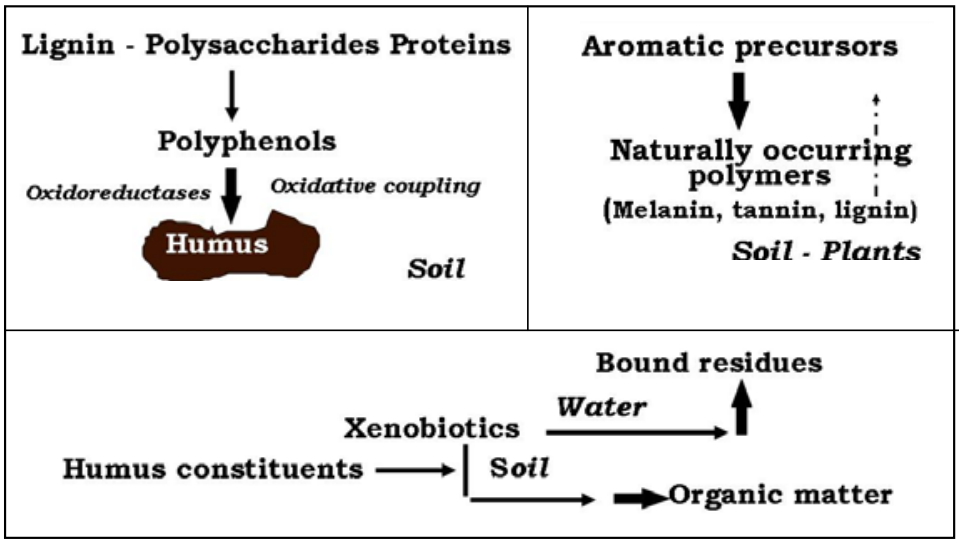

b)

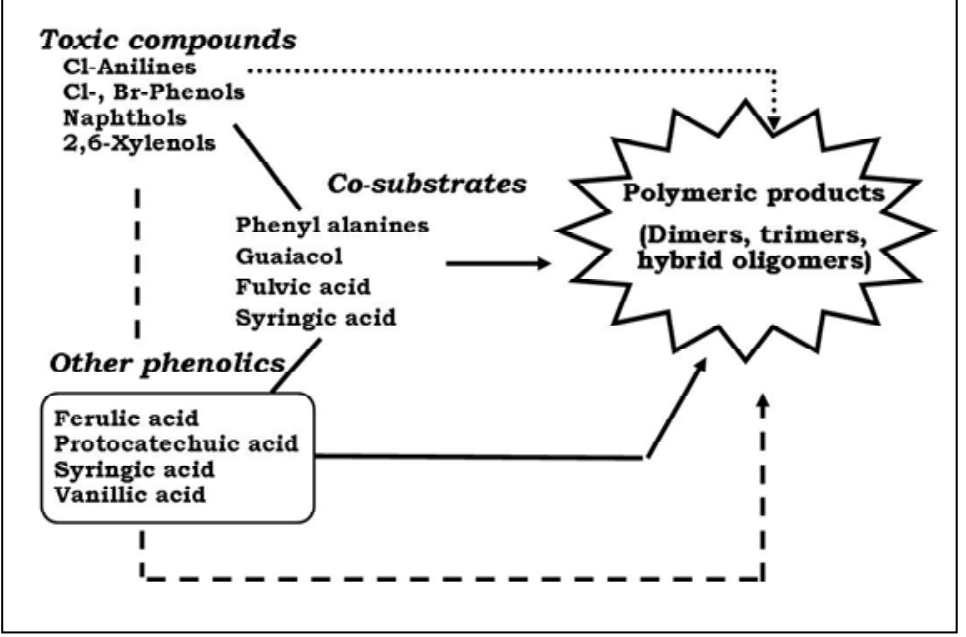

Figure 4. Role of oxidative enzymes in the environment. a) Involvement of oxidative enzymes in synthetic and degradation mechanisms occurring in soil, plant and water; b) detoxification by oxidative enzymes by polymerization and cross-reaction of different pollutants.

Rubilar et al., 2008). These organisms are very effective, because they are robust organisms and may tolerate higher concentrations of pollutants than bacteria. Besides, white-rot fungi are widespread in nature, grown by hyphal extension and extend in the soil with growth and, therefore, can reach soil pollutants in ways that bacteria cannot. Their growth may occur also with inexpensive substrates such as agricultural crop wastes that can be easily added as nutrients to the contaminated site. Fungal degradation occurs extra-cellularly in two steps: firstly 
by the action of the hydrolytic system, that produces hydrolases responsible for degradation of macromolecular substances, and subsequently by the action of the oxidative, lignolytic system. The oxidative lignolytic system is a complex, non-specific, very powerful extracellular enzymatic system and, under nutrientlimiting conditions, is capable of degrading lignolytic compounds, dyes and several environmental pollutants that cannot be degraded by other microorganisms (Reddy, 1995; Pointing, 2001; Sanchez, 2009).

White-rot fungi are able to produce different patterns of oxidative enzymes depending on the agricultural residues in which they grow and develop. For instance, Trametes versicolor, one of the most common Basidyomicete with lygninolytic ability, produces laccase in the presence of white wood shaving, carozo maize and compost of gardening wheat straw. Laccase, xylanases, MnP, cellobiose dehydrogenase are mainly produced with grape seeds, barley bran and wood shavings, while laccase, MnP, glucose oxidase, glyoxal oxidase and quinone oxidoreductase are delivered if sugar cane bagasse is the main residue. By contrast, the Ascomycete Aspergillus niger generates xylanases and cellulases with the same agricultural residue (Sanchez, 2009).

Several are the pollutants potentially transformed and detoxified by the oxidative enzymes (Table 2). They include phenols, polyphenols and substituted polyphenols, PCBs, PAHs, dyes and azodyes.

Azo dyes are extensively used in textile, food, pharmaceutical, printing, and cosmetic industries. They are carcinogenic and teratogenic, and as such, pose a problem to environmental and human health. Traditional technologies often using hazardous chemicals to decolorize and/or remove azo-dyes may have adverse and damaging effects. Therefore, the use of an enzyme capable of oxidizing and/or eliminating azo dyes is an appealing alternative to these drastic and unsafe treatments.

Once again, white-rot fungi help to approach and solve the problem. They are good dye-degraders, and different fungal cultures have the interesting characteristic for practical application of producing different profiles of lignin-mineralizing enzymes and patterns of their expression depending upon the chemical structure and functional groups of the dyes being degraded (Asgher et al., 2008). For instance, with Remazol Brillant Blue Royal (RBBR) Funalia trogii produces laccase as the main enzyme whereas manganese peroxidase is mainly produced by Lentinula edodes.

Among oxidative enzymes, laccases have received a lot of attention from several researchers due to their peculiar catalytic properties. Laccases (benzenediol: oxygen oxidoreductases, EC 1.10.3.2) are multi-copper oxidases that catalyze the one electron oxidation of substituted phenols, anilines, and aromatic thiols to the corresponding radicals with the concomitant reduction of molecular oxygen to water. These radicals produce polymeric products by self-coupling or cross-coupling with other molecules, and dechlorination, demethoxylation and decarboxylation during coupling and polymerization of differently substituted substrates may also occur. Less or nonreactive substances, including also highly recalcitrant compounds, may also be transformed in the presence of highly reactive substances acting as mediators such as ABTS, HBT (1hydroxybenzentriazole) and others (Gianfreda et al., 1999; Gianfreda and Rao, 2004). Therefore, these enzymes appear suitable and versatile catalysts, very useful for the application in several 
Table 2. Application of oxidative enzymes (Adapted from Duran and Esposito, 2000).

\begin{tabular}{|c|c|c|}
\hline Enzymes & Source & Applications \\
\hline \multirow[t]{3}{*}{ Peroxidase } & Horseradish & $\begin{array}{l}\text { Degradation of phenols, chlorophenols, anilines. Decontamination of Kraft effluents and } \\
\text { black liquor, biosensor phenol determination, dewatering of slimes }\end{array}$ \\
\hline & Artromyces ramosus & Degradation of phenols, polyaromatics and herbicides. Polymerization of humic acids \\
\hline & Plant materials & Water decontamination \\
\hline Chloroperoxidase & Caldariomyces funago & Phenolic compounds oxidation. Biosensor chlorophenol detection \\
\hline Lignin peroxidase & $\begin{array}{l}\text { Phanerochaete chrysosporium } \\
\text { Chrysonilia sitophila }\end{array}$ & $\begin{array}{l}\text { Degradation of aromatic compounds and phenolic materials. Remediation of Kraft effluent } \\
\text { Kraft effluent decontamination }\end{array}$ \\
\hline \multirow[t]{3}{*}{$\begin{array}{l}\text { Manganese } \\
\text { peroxidase }\end{array}$} & Phanerochaete chrysopsorium & Degradation of phenols, lignin, pentachlorophenol, and dyes \\
\hline & $\begin{array}{l}\text { Nematolona frowardi e Phebia } \\
\text { radiata }\end{array}$ & Lignin degradation \\
\hline & Lentinula edodes & Degradation of chlorophenol and diuron \\
\hline \multirow[t]{2}{*}{ Tyrosinase } & Sigma & $\begin{array}{l}\text { Phenol biosensor. Degradation of phenols and amines and removal of xenobiotic } \\
\text { compounds. Oxidation of catechol and polymerization of phenolic compounds }\end{array}$ \\
\hline & Agaricus bisporus & Catechol oxidation \\
\hline \multirow[t]{6}{*}{ Laccase } & Trametes hispida & Dyes decoloration \\
\hline & Pyricularia oryzae & Azo-dyes degradation \\
\hline & Trametes versicolor & Textile effluent degradation, chlorophenols and urea derivatives degradation \\
\hline & Cerrena unicolor & Phenol detoxification, 2,4-dichlorophenol degradation \\
\hline & Pycnoporus cinnabarinus & Benzopyrenes degradation \\
\hline & Plant materials & Chlorophenols, xenobiotic binding to humus \\
\hline \multirow[t]{2}{*}{$\begin{array}{l}\text { Catechol } \\
\text { dioxygenase }\end{array}$} & Comamonas testosteroni & Chlorophenol oxidation, diuron degradation \\
\hline & Pseudomonas pseudoalcaligenes & Polychlorinated biphenyls, chlorothanes \\
\hline \multirow[t]{3}{*}{$\begin{array}{l}\text { Phenoloxidase- } \\
\text { like }\end{array}$} & Gloeophyllum trabeum & Kraft effluent decontamination \\
\hline & $\begin{array}{l}\text { Trametes versicolor } \\
\text { Phanerochaete chrysosporium }\end{array}$ & Chlorinated compounds degradation \\
\hline & Thermoascus aurantiacus & Kraft effluent \\
\hline
\end{tabular}


biotechnological processes (Rodríguez Couto and Toca Herrera, 2006; Rodríguez Couto, 2009).

Several studies were performed by Gianfreda and co-workers on the isolation and characterization of laccases from different fungal sources and on their potential application for the detoxification of different pollutants (Gianfreda and Bollag, 1994; Luterek et al., 1997; Gianfreda et al., 1998 ; Filazzola et al., 1999; Gianfreda et al, 1999 ; Durán et al., 2002; Gianfreda and Bollag, 2002 ; Bollag et al., 2003; Gianfreda et al., 2003; Gianfreda et al., 2006; Canfora et al., 2008; Iamarino et al., 2009).

An interesting application of laccase was in the treatment of a waste produced in large amounts in Mediterranean countries. Olive oil is a typical Mediterranean product. Indeed, over 95\% of the worldwide olive oil production, which is about 2.5 million tons per year, is produced in the Mediterranean area. In the olive industry, two types of wastes are produced, olive oil mill waste waters (OMW) and olive husk. Olive husk may be used for combustion, as compost or catalyst (Greco et al., 1999) whereas OMW are pollutants and not easily recyclable. OMW have several damaging properties such as intensive violet-dark brown up to black color, strong specific olive oil smell, high degree of organic pollution (COD values up to $220 \mathrm{~g} \mathrm{l}^{-1}$ ) at a COD/BOD5 ratio between 2.5 and 5 (hardly degradable), slightly acidic $\mathrm{pH}$ between 3 and 5.9, high content of phytotoxic compounds such as polyphenols (up to $80 \mathrm{~g} \mathrm{l}^{-1}$ ), high content of residual oil and solid matter (total solids up to $20 \mathrm{~g} \mathrm{l}^{-1}$ ), very high concentrations of the antioxidants present in the olive oil. Moreover, OMW production is in a restricted geographical area (most of which has also a tourist character) and in a very limited time period (about 3 months, from October to January).

These properties make OMW and their treatment a serious problem with several negative impacts on soil and water quality, hence on agriculture, environment and health. However, OMW are also a source of valuable compounds with antioxidant activity, useful for applicable purposes. Consequently, OMW could be safely used provided that their toxicity has been reduced or even eliminated with low-cost, environmental-friendly treatments such as those based on the use of enzymes.

A laccase from the fungus Trametes versicolor was tested in the presence of various phenolic compounds (caffeic acid, catechol, hydroxytyrosol, methylcatechol, protocatechuic acid, syringic acid, $m$ tyrosol, 3-hydroxybenzoic acid, 3hydroxyphenylacetic acid, 2,6-dihydroxybenzoic acid, 4-hydroxybenzaldehyde) typically present in OMW from different origins (Canfora et al., 2008). According to their response to 24-h laccase action, the eleven phenolic compounds were classified into three groups: reactive ( 88 from $100 \%$ transformation), intermediate reactive (transformation lower than 50\%) and recalcitrant (not transformed at all).

The enzyme was able to transform the eleven substrates even when they were present in a mixture, and also a phenolic extract from a Moroccan OMW sample. In particular, the transformation of hydroxytyrosol, a particularly abundant phenol in OMW, was quite independent of the complexity of the reaction mixture, whereas its presence influenced the transformation of the other phenols. By contrast, the removal of methylcatechol or $m$-tyrosol was strongly affected by the simultaneously presence of other phenols in the reaction mixture.

The same enzyme was applied to two olive-mill waste water samples differing 
for/in complexity and composition (Iamarino et al., 2009). The enzyme was able to reduce the contents of several phenols present in the two wastes. In addition, phytotoxicity tests with Lepidium sativum and Lycopersicon esculentum seeds and antibacterial toxicity tests with Bacillus megaterium before and after the catalytic treatment demonstrated that a) monomeric phenols were certainly but not exclusively responsible of OMW phytotoxicity, whereas their removal led to a quite complete elimination of the toxicity toward bacterial growth; b) other components not removable by the oxidative catalyst very likely contribute to OMW phytotoxicity; c) the choice of the vegetal species to use in toxicity tests might be crucial for correct and easily interpretable results. The obtained overall results suggest that laccases are effective in the transformation of simple and complex phenolic mixtures and may provide useful information on the possible use of oxidative enzymatic catalysts for the efficient treatment of complex aqueous wastes such as those deriving from the olive industry.

Heavy metals are very often essential trace elements for living organisms. However, when present in the environment at high levels they may produce environmental and health problems because of their high toxicity. For instance, this is the case of chromium (Cheung and Gu, 2007). This element is widely used in several industries and its hexavalent species $\left(\mathrm{Cr}^{6+}\right)$ is a toxic, mutagenic and carcinogenic chemical. It is highly soluble, hence mobile and biologically available in the ecosystems. US EPA has identified $\mathrm{Cr}^{6+}$ as one of the 17 chemicals posing the greatest threat to humans. By contrast, its reduced trivalent form $\left(\mathrm{Cr}^{3+}\right)$ is much less toxic and insoluble.
Microorganisms possess enzymes capable of effectively reducing $\mathrm{Cr}^{6+}$ to $\mathrm{Cr}^{3+}$ under both aerobic and anaerobic conditions (Figure 5). $\mathrm{Cr}^{6+}$ reductases, $\mathrm{ChrR}$ and YieF, two soluble enzymes, have been recently purified from Pseudomonas putida MK1 and Escherichia coli, respectively. These two enzymes are a promising alternative approach for bioremediation of chromium six in several environments, provided that their direct application can be afforded possibly as immobilized enzymes.

\section{POSSIBLE STRATEGIES FOR OVER- COMING PROBLEMS ASSOCIATED WITH THE USE OF ENZYMES}

The use of an enzyme is possible if the product of the enzyme-mediated reaction is less toxic than the substrate. Moreover, if the detoxification requires a multistep process, i.e. many enzymes acting sequentially, only specific microorganisms are suitable for achieving decontamination. Even if enzymes require cofactors, their use may be problematic, unless a preparation containing both the enzyme and the respective cofactor is used. Another problem in the use of enzymes to detoxify organic-polluted soil is given by the rapid degradation of the free enzyme by proteases released by soil microorganisms.

Other drawbacks may limit the use of enzymes for practical application and in situ remediation of contaminated environments.

In natural environments, disadvantages that may hinder or diminish the catalytic potential of enzymatic catalysts may depend on both the pollutants to be transformed and the enzymes. In a polluted site, mixtures or composed combinations of many organic 


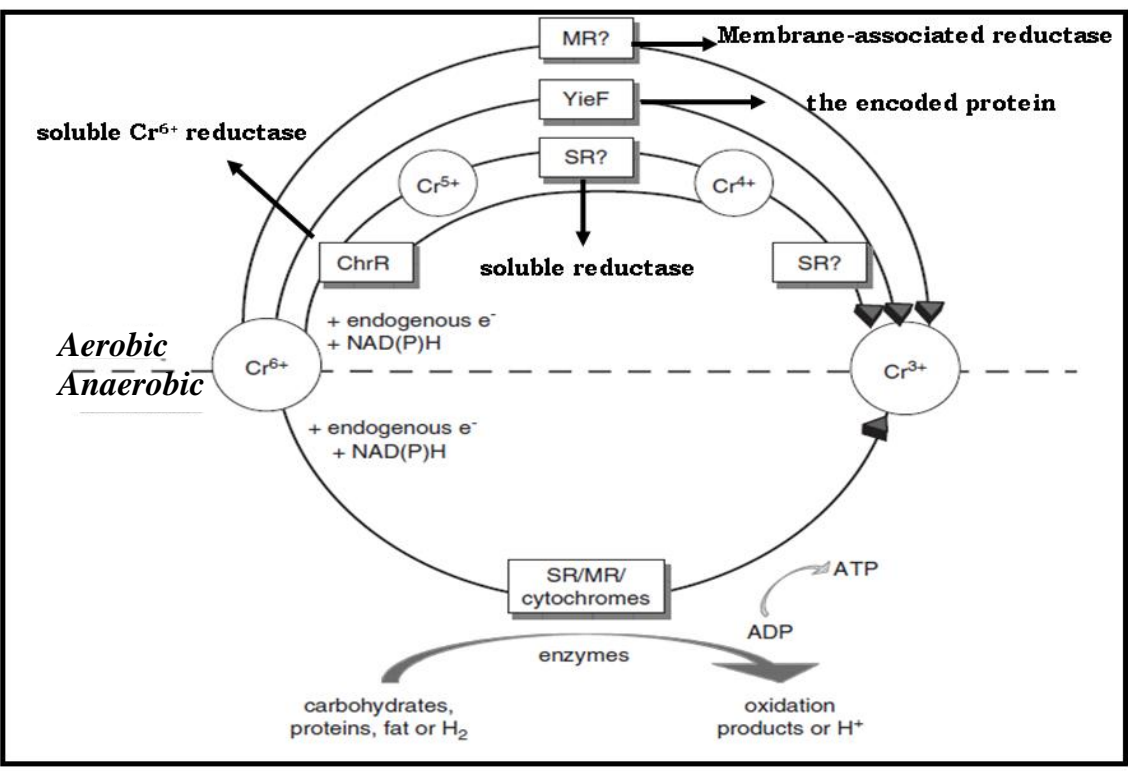

Figure 5. Mechanisms of enzymatic $\mathrm{Cr}^{6+}$ reduction under aerobic (upper) and anaerobic (lower) conditions.

(and inorganic) contaminants, rather than a single pollutant, are present and the complexity of the pollution may entail possible negative or positive, synergistic effects on the enzyme efficiency.

Enzymes may reduce or even lose their activity upon pollutant transformation or they may present a low stability and survival under very often harsh environmental conditions. If their repeated use is required, enzymes may present low reusability, thus decreasing the efficiency of the whole treatment. In addition, if isolated enzymes are used, the cost of enzyme isolation and purification greatly hampers their practical application, mainly when their continuous feeding is needed.

One possibility to overcome several disadvantages linked to the use of free enzymes is to improve both a) the functioning of the chosen enzyme by changing the conditions under which the enzyme displays its catalytic activity or b) the enzyme itself by optimizing its intrinsic and inherent catalytic features by acting on its structure and catalytic function.

For instance, with particularly recalcitrant pollutants, the enzyme efficiency may be greatly enhanced by the presence of additional compounds acting as co-substrates or mediators. As reported above, for example, this is the case of laccase, whose potential may be improved by the addition of several mediators (Gianfreda et al., 1999; Gianfreda and Rao, 2004)

Torres-Duarte et al. (2009) investigated the transformation of twelve halogenated pesticides (i.e. 2,4-DB, bromofenoxim, bromoxynil, dichlofenthion, dichlorophen, dinoterb, diuron, linuron, niclosamide, pentachlorophenol, picloram, and propanil) by a laccase from Coriolopsis gallica in the presence of nine different mediators (syringaldehyde, aceto- 
syringone, cinnamic acid, ABTS, TEMPO, 1-hydroxybenzotriazole, vainillin, coniferyl alcohol, gallic acid) at different mediator-substrate rates.

Acetosyringone and syringaldehyde showed to be the best mediators. The highest pesticide transformation rates were obtained with a mediator-substrate proportion of $5: 1$, one of the lowest reported so far for the laccase-mediator systems. An oxidative dehalogenation was involved in the catalytic mechanism, as assessed by the analysis of the main product from the dichlorophen transformation. Moreover, adducts formed between the mediator syringaldehyde and pesticides dichlorophen or bromoxynil after enzymatic oxidation. The overall results indicate that the laccase-mediator system seems to be a good alternative for the transformation of recalcitrant halogenated pesticides. Indeed, dehalogenation of pesticides and formation of pesticide-mediator adducts occurred, both contributing to the reduction of pesticide environmental impact.

The addition of 1-hydroxybenzotriazol (HBT) to a laccase from Trametes trogii was the most effective among 11 mediators (i.e. 2,6-dimethoxyphenol: DMP), HBT, syringaldehyde, syringate, vanillin, vanillate, acetosyringone, $\mathrm{m}-, \mathrm{O}-$ and $p$-coumarate) in the decolorization and detoxification of a textile industry effluent (Khlifi et al., 2010). However, toxicity tests performed with the Microtox assay showed that crude and laccase-HBT treated effluent retained toxicity, whereas acetosyringone, a natural mediator, although being less efficient, significantly reduced the toxicity of the effluent.

Another approach to improve the performance of enzymes in the detoxification of pollutants is the use of enzymes immobilized on natural and synthetic supports of different nature and through different immobilization mechanisms. Immobilized enzymes have usually a long-term operational stability, being very stable toward physical, chemical, and biological denaturing agents. Furthermore, they may be reused and recovered at the end of the process (Gianfreda and Bollag, 1994; Durán and Esposito, 2000; Durán et al., 2002; Gianfreda and Bollag, 2002).

Khan and Husain (2007) utilized a potato polyphenol oxidase preparation adsorbed on Celite for the treatment of wastewater/dye effluent contaminated with reactive textile and non-textile dyes, Reactive Blue 4 and Reactive Orange 86, and compared its efficiency and stability with the free enzyme (Khan and Husain, 2007). The immobilized enzyme showed a higher efficiency in decolorizing not only individual textile dyes, but also their complex mixtures (containing different combination of up to four dyes) and dyeing effluent as compared with the soluble enzyme. Immobilized enzyme showed also a higher stability against several denaturing conditions and significantly higher decolorizing activity than the free form toward non-textile dyes.

A very interesting immobilization technique was implemented with laccase from Trametes versicolor by Gitsow et al. (2008). Enzymatic nanoreactors were contructed through noncovalent envelopment of the enzymatic protein by amphiphilic linear-dendritic AB or ABA copolymers. The glycoside fragments in the native enzyme served as anchor sites for the linear-dendritic copolymers, as assessed by control tests carried out with the deglycosylated protein. The immobilization improved the catalytic activity compared with the native enzyme (77-85 nkat $\mathrm{mL}^{-1}$ vs 60 nkat $\mathrm{mL}^{-1}$, respectively). In addition, the immobilized enzyme was more stable at elevated temperatures up to $70^{\circ} \mathrm{C}$ and able to 
effectively oxidize phenolic compounds (syringaldazine) and hydrophobic polyaromatic hydrocarbons (anthracene and benzo[a]pyrene) (Gitsow et al., 2008).

Degradative enzymes with new or improved activities and stability under selected conditions can be generated by genetic engineering strategies like rational site-directed mutagenesis and various DNA-shuffling methods (i.e. the random fragmentation of a population of mutant genes of a certain family followed by random reassembly). Enzymes can be modified by directed evolution or by sitespecific mutagenesis to improve existing biodegradation pathways or to develop biocatalytic processes for the production of useful products. For the degradation of recalcitrant compounds where no natural pathways are known, novel pathways can be generated by combining pathway 'cassettes' from various genetic sources (Parales and Ditty, 2005).

However, limitations are present for applying biomolecular engineering techniques. For instance, research is usually focused on altering enzymes that can perform a reaction similar to the desired one, but it might be difficult to apply biomolecular engineering to the bioremediation of novel pollutants, which are not known to be biodegradable. Nevertheless, it might be possible in the future when our knowledge of the protein structure-function, folding, mechanism and dynamics will be significantly improved. Even if a genetically engineered microorganism (GEM) with enhanced capabilities and producing the desired enzyme is successfully created by biomolecular engineering, it still faces a number of significant constraints regarding its application. GEMs or their enzymatic components released into the environment may have a decreased fitness level and may not survive due to the extra energy demands imposed by the presence of foreign genetic material in the cell.
Furthermore, public acceptability of releasing GEMs into the environment has led to strict regulations by government bodies (EPA). As a result, few isolated microorganisms have reached the stage of field application (Ang et al., 2005).

\section{PLANTS AND THEIR ASSOCIATED ENZYMES AS DECONTAMINATING AGENTS}

An appealing alternative for overcoming some of the drawbacks related to the use of enzymes in in situ remediation of polluted environments is phytoremediation. Phytoremediation is the in situ use of plants, their enzymatic system, their roots and associated microorganisms to degrade, contain or render harmless pollutants present in different environmental systems (soil, sediments, groundwater, and air).

With respect to their direct roles in remediation processes, plants may utilize different mechanisms to efficiently remove both organic and inorganic pollutants from a polluted environment: a) rhizofiltration; b) absorption; c) concentration and precipitation of heavy metals by roots; d) phytoextraction, i.e. extraction and accumulation of pollutants in plant tissues including roots and leaves; e) phytodegradation i.e. degradation of complex organic molecules in $\mathrm{CO}_{2}$ and $\mathrm{H}_{2} \mathrm{O}$ and their incorporation in plant tissues; f) rhizodegradation or plantassisted bioremediation i.e. stimulation of microbial and fungal degradation by the release of root enzymes and exudates in the rhizosphere; and g) phytostabilitation, i.e. adsorption and precipitation of pollutants (mainly metals) with a consequent reduction of their mobility.

An interesting phenomenon is the synergic interaction between plants and microorganisms that specifically occurs in the soil environment influenced by plantroots, or rhizosphere. 
Since plants may be deficient in catabolic pathways for the complete degradation of pollutants compared with microorganisms, research efforts have been devoted to engineer plants with genes that can confer them additional and enhanced degradation abilities. The efficacy of phytoremediation can be directly enhanced by overexpressing the genes involved in metabolism, uptake, or transport of specific pollutants in plants. Moreover, suitable genes may be expressed in roots to enhance the rhizodegradation of highly recalcitrant pollutants (Abhilash et al., 2009).

Several transgenic plants enriched with genes from humans, microbes, plants and animals have been produced and have shown enhanced abilities of metabolizing several xenobiotics. For instance, human and mammalian (e.g. rat, mouse, rabbit) CYP450 isoenzymes (CYP1, CYP3) genes have been inserted in Nicotiana tabaccum, Solanum tuberosum, Oryza sativa or Arabidopsis thaliana and the modified plants have shown either herbicide resistance (e.g. tolerance towards atrazine, simazine) or enhanced metabolization of xenobiotics (herbicides or volatile halogenated hydrocarbons) and their subsequent removal from contaminated soil and groundwater (Abhilash et al., 2009).

Another most promising approach to enhancing phytoremediation ability is the production of transgenic plants secreting enzymes for the rhizoremediation of xenobiotics (Abhilash et al., 2009). In these plants xenobiotics degrading genes have been inserted in their root system and therefore plants have achieved the capability of secreting degrading enzymes into the rhizosphere. This method has the unquestionable advantage that pollutants have not been up taken by plants to be degraded; instead, the secreted enzymes can degrade the pollutants in the rhizospheric zone (Figure 6). Additional rhizosphere effects may contribute to enhance pollutant degradation. Microbial density, diversity and/or metabolic activity may increase because of the release of plant root exudates, mucigel and root lysates. In addition, the physical and chemical properties of the contaminated soil can be increased by plants as well as by the contact between the root-associated microorganisms and the soil contaminants (Figure 6).

However, the use of plants alone can present some limitations. Recently, application of plant growth-promoting rhizobacteria (PGPR), i.e. bacteria capable of promoting plant growth by colonizing the plant root has received much attention for their use in bioremediation of polluted soils (Zhuang et al., 2007). Several examples of bioremediation of inorganic and organic contaminants by PGPR are now available. Various bacteria associated with plants like wheat, alfalfa, tall fescue, Brassica juncea, ndian mustard, canola and others have been successfully used in the bioremediation of crude oil, PAHs, total petroleum hydrocarbons, TCE, PCBs and lead, zinc, nichel, cadmium (Zhuang et al., 2007). Therefore, phytoremediation in conjunction with rhizospheric microbes may provide sustainable, eco-friendly and efficient rhizoremediation processes for contaminated ecosystems.

\section{CONCLUSIONS}

In conclusion, several are the fields in which enzymes can be applied (Figure 7). Enzymes present environmental advantages against chemicals and microorganisms. They are: the biotransformation does not generate toxic side products as is often the case with chemical and some microbiological processes; the enzymes are digested, in situ, by the indigenous microorganisms 


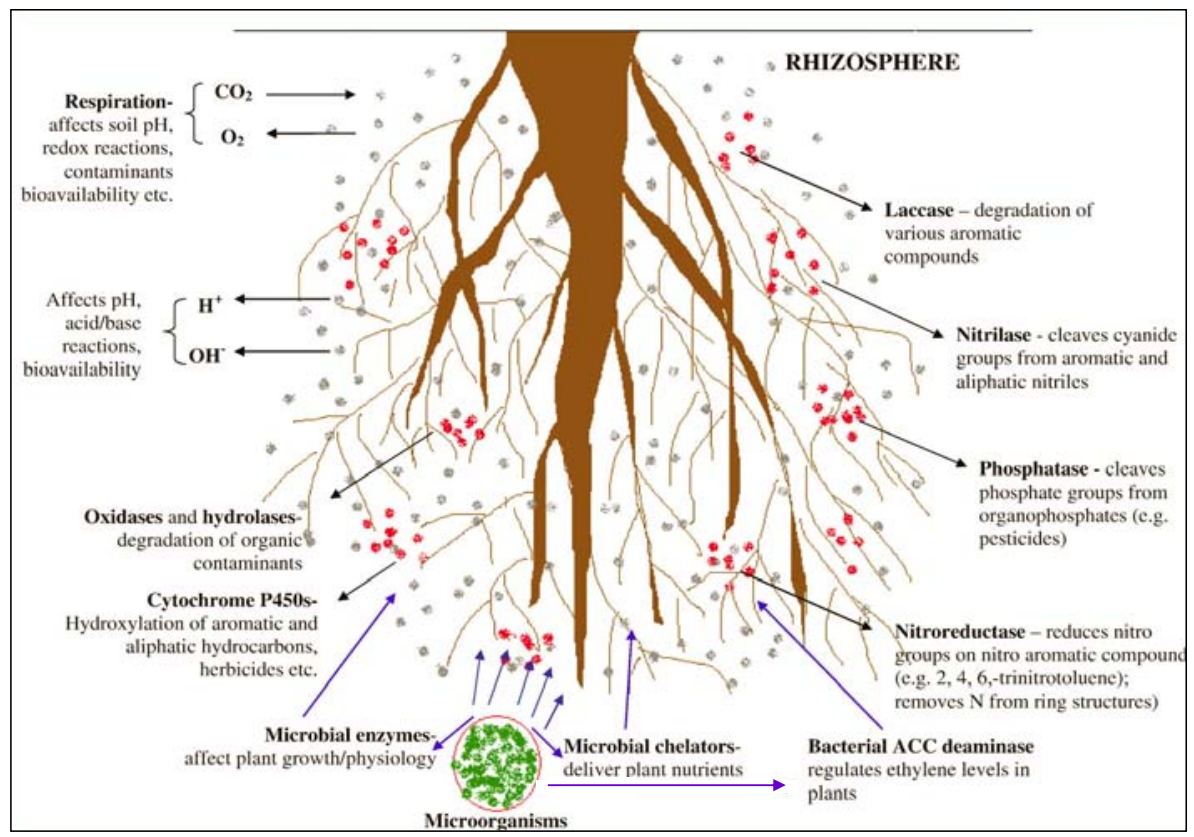

Figure 6. Enzymatic and microbial activities responsible for the enhanced remediation in rhizospheric zone (From Abhilash et al., 2009).

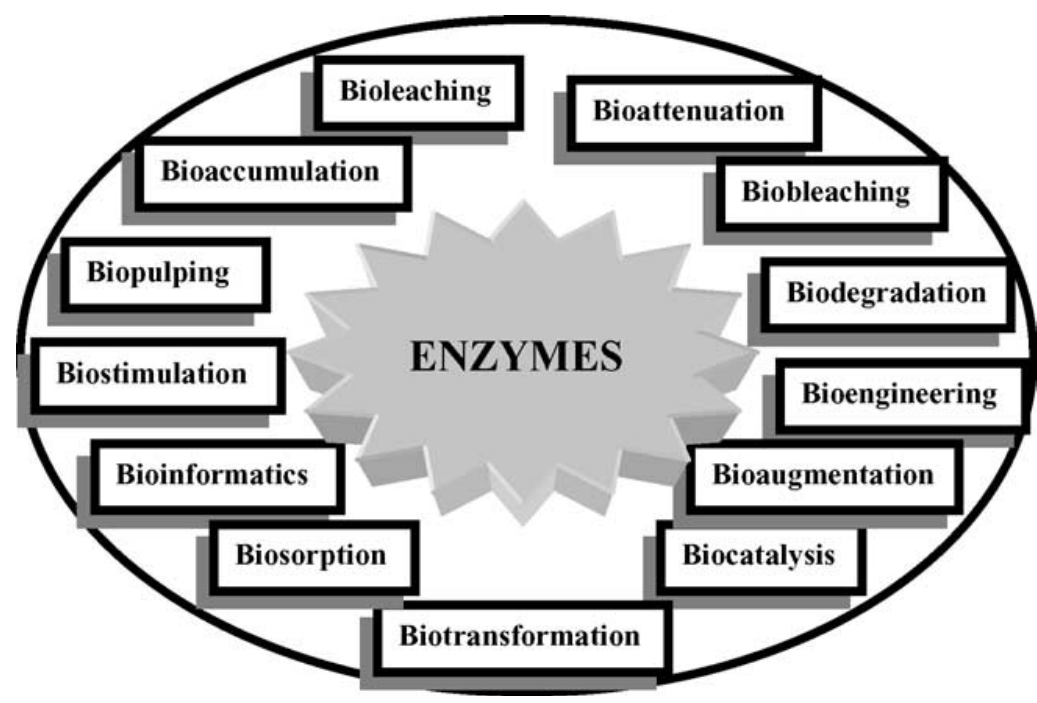

Figure 7. Overview of the enzymology of biological remediation (From Whiteley and Lee, 2006). 
after the treatment; the requirement to enhance bio-availability by the introduction of organic co-solvents or surfactants is much more feasible from an enzymatic point of view than using whole cells; the production of enzymes at a higher scale, with enhanced stability and/or activity and at a lower cost is feasible by using recombinant-DNA technology.

However, the enzyme performance for in situ bioremediation of contaminated groundwater and soils may be affected by many factors. They are:

- chemistry and toxicity of contamination,

- source and concentration of pollutants,

- solubility, transport, adsorption, dispersion and volatility of pollutant compounds,

- detection, determination and monitoring of pollutants,

- chemistry, physics and microbiology of groundwater and soil,

- chemistry and mechanics of soil at the contaminated site,

- hydrogeology and hydrology of the contaminated site,

- limitations of environmental standards for water and soil,

- environmental conditions, nutrient sources and presence of electron acceptors,

- and mainly the biodegradability of contaminants.

Rapid progresses in various pathways, operative in microbes for the degradation of pollutants, have thrown more light on their mechanisms, and pathways have been characterized to develop sustainable bioremediation strategies for polluting compounds. However, the structures of enzymes, regulatory aspects and molecular biology still require thorough understanding. Moreover, a great deal of work is still required to firmly establish total understanding of the molecular basis for catabolic sequences, to limit inactivation of enzymes at high threshold concentration of xenobiotics, to increase compounds bioavailability in natural ecosystems, and to improve the functional ability of the selected enzyme within a narrow range of physico-chemical conditions.

The scope of bioremediation is to decrease the concentration of organic pollutants at undetectable levels or, if measurable, lower than the limits established as safe or tolerable by regulatory agencies. Consequently several criteria concerning a) the selected agent to perform the bioremediation process, b) the toxicity of the end-products and c) the conditions at the site, favorable or not to the process, must be met to be bioremediation seriously considered as a practical method for treatment. In addition, the feasibility of the bioremediation program has to be evaluated by considering its real applicability, its possible limitations and drawbacks and its advantages.

Only when some or all these aspects will be addressed, an effective, successful, productive, and nondeleterious of environment quality and costly-convenient bioremediation process will be performed.

\section{REFERENCES}

Abhilash, P.C., Jamil, S., Singh, N. 2009. Transgenic plants for enhanced biodegradation and phytoremediation of organic xenobiotics. Biotechnol. Adv. 27, 474-488.

Alcalde, M., Ferrer, M., Plou, F. J., Ballesteros, A. 2006. Environmental biocatalysis: from remediation with enzymes to novel green processes. Trends Biotechnol. 24, 281-287. 
Ang, E. L., Zhao, H., Obbard, J. P. 2005. Recent advances in the bioremediation of persistent organic pollutants via biomolecular engineering. Enzyme Microb. Technol. 37, 487496.

Asgher, M., Nawaz Bhatti, H., Ashraf, M., Legge, R. L. 2008. Recent developments in biodegradation of industrial pollutants by white rot fungi and their enzyme system. Biodegradation 19, 771-783.

Banerjee, A., Sharma, R., Banerjee, U. C. 2002. The nitrile-degrading enzymes: current status and future prospects. Appl. Microbiol. Biotechnol. 60, 33-44.

Blacksmith Institute 2007. The World's Worst Polluted Places. The Top Ten of The Dirty Thirty, Blacksmith Institute, New York, www.blacksmithinstitute.org.

Bollag, J.-M., Bollag, W. B. 1995. Soil contamination and the feasibility of biological remediation. In: H. D. Skipper, R. F. Turco (eds). Bioremediation: Science and Applications, SSSA Special Publication 43. ASA, CSSA, and SSSA, Madison, WI, pp: 1-12.

Bollag, J.-M., Chu, R., Rao, M. A., Gianfreda, L. 2003. Enzymatic oxidative transformation of chlorophenol mixtures. J. Environ. Qual. 32, 6271.

Bumpus, J.A. 1993. White-rot fungi and their potential use in soil bioremediation processes. In: J.-M. Bollag, G. Stotzky (eds). Soil Biochemistry. Marcel Dekker, New York, pp: 65-100.

Canfora, L., Iamarino, G., Rao, M. A., Gianfreda, L. 2008. Detoxification of natural and synthetic phenolic mixtures by Trametes versicolor laccase. J. Agric. Food Chem. 56, 1398-1407.

Cheung, K. H., Gu, J.-D. 2007. Mechanism of hexavalent chromium detoxification by microorganisms and bioremediation application potential: A review. Int. Biodeter. Biodegrad. 59, $8-15$.

Cipollone, R., Ascenzi, P., Frangipani, E., Visca, P. 2006. Cyanide detoxification by recombinant bacterial rhodanese. Chemosphere 63, 942-949.

Coppella, S.J., Cruz, N.D., Payne, G.F., Pogell, B.M., Speedie, M.K. Karns, J.S., Sybert, E.M., Connor, M.A. 1990. Genetic engineering approach to toxic waste management case study for organophosphate waste treatment. Biotechnol. Prog. 6, 76-81.
Durán, N., Esposito, E. 2000. Potential applications of oxidative enzymes and phenoloxidase-like compounds in wastewater and soil treatment: a review. Appl. Catal. B. Enzym. 28, 83-99.

Durán, N., Rosa, M.A., D’annibale, A. Gianfreda, L. 2002. Applications of laccases and tyrosinases (phenoloxidases) immobilized on different supports: a review. Enzyme Microb. Technol. 31, 907-931.

Filazzola, M.T., Sannino, F., Rao, M.A., Gianfreda, L. 1999. Effect of various pollutants and soil-like constituents on laccase from Cerrena unicolor. J. Environ. Qual. 28, 19291938.

Gianfreda, L., Bollag, J.-M. 1994. Effect of soils on the behaviour of immobilized enzymes. Soil Sci. Soc. Am. J. 58, 1672-1681.

Gianfreda, L., Bollag, J.-M. 2002. Isolated enzymes for the transformation and detoxification of organic pollutants. In: R.G. Burns, R. Dick (eds). Enzymes in the Environment: Activity, Ecology and Applications. Marcel Dekker, New York, pp: 491-538.

Gianfreda, L., Rao, M.A. 2004. Potential of extra cellular enzymes in remediation of polluted soils: a review. Enzyme Microb. Technol. 35, 339-354.

Gianfreda, L., Rao, M. A. 2008. Bonifica di suoli contaminati e depurazione dell'acqua. In: M. Gennari, M. Trevisan (eds). Agrofarmaci. Conoscenze per un Uso Sostenibile. Oasi Alberto Perdisa, Bologna, Italy, pp: 521-564.

Gianfreda, L., Sannino, F., Filazzola, M. T., Leonowicz, A. 1998. Catalytic behavior and detoxifying ability of a laccase from the fungal strain Cerrena unicolor. J. Mol. Catal. B: Enzym. 14,13-23.

Gianfreda, L., Xu, F., Bollag, J.-M. 1999. Laccases: a useful group of oxidoreductive enzymes. Biorem. J. 3, 1-26.

Gianfreda, L., Sannino, F., Rao, M. A., Bollag, J.-M. 2003. Oxidative transformation of phenols in aqueous mixtures Water Res. 37, 3205-3215.

Gianfreda, L., Iamarino, G., Scelza, R., Rao, M.A. 2006. Oxidative catalysts for the transformation of phenolic pollutants: a brief review. Biocatal. Biotransform. 24, 177-187.

Gitsov, I., Hamzik, J., Ryan, J., Simonyan, A., Nakas, J. P., Omori, S., Krastanov, A., Cohen, T., Tanenbaum, S. W. 2008. Enzymatic nanoreactors for environmentally benign 
biotransformations. 1. Formation and Catalytic Activity of Supramolecular Complexes of Laccase and Linear-Dendritic Block Copolymers. Biomacromolecules 9, 804-811.

Greco, G. jr., Toscano, G., Cioffi, M., Gianfreda, L., Sannino F. 1999. Dephenolisation of olive mill waste-waters by olive husk. Water Res. 33, 3046-3050.

Karam, J., Nicell, J. A. 1997. Potential application of enzymes in waste treatment. J. Chem Technol Biotechnol. 69, 141-153.

Khan, A. A., Husain, Q. 2007. Decolorization and removal of textile and non-textile dyes from polluted wastewater and dyeing effluent by using potato (Solanum tuberosum) soluble and immobilized polyphenol oxidase. Biores. Technol. 98, 1012-1019.

Khlifi, K., Belbahri, L., Woodward, S., Sayadi, S., Mechichi, T. 2010. Decolourization and detoxification of textile industry wastewater by the laccase-mediator system. J. Hazard. Mater. $175,802-808$.

Iamarino, G., Rao, M. A., Gianfreda, L. 2009. Dephenolization and detoxification of olive-mill wastewater (OMW) by purified biotic and abiotic oxidative catalysts. Chemosphere 74, 216-223.

Luterek, J., Gianfreda, L., Leonowicz, A. 1997. Screening of wood-rotting fungi for laccaseproducing induction by ferulic acid, partial purification and immobilization of laccase from the high laccase-producing strain, Cerrena unicolor. Acta Microbiol. Pol. 46, 297-311.

Martínková L., Vejvoda V., Kaplan O., Kubáč D., Malandra A., Cantarella M., Bezouška K. , Křen V. 2009. Fungal nitrilases as biocatalysts: Recent developments. Biotechnol. Adv. 27, 661670

Mulbry, W. W., Eaton, R. W. 1991. Purification and characterization of the N-methylcarbamate hydrolase from Pseudomonas strain CRL-OK. Appl. Environ. Microbiol. 57, 3679-3682.

Nakamura, K., Tomita, T., Abe, N., Kamio, Y. 2001. Purification and characterization of an extra cellular poly(L-lactic acid) depolymerase from a soil isolate, Amycoatopsis sp. Strain K104-1. Appl. Environ. Microbiol. 67, 345-353.

Nannipieri, P., Bollag, J.-M. 1991. Use of enzymes to detoxify pesticide-contaminated soils and waters. J. Environ. Qual. 20, 510-517.
Nicell, J.A. 2001. Environmental applications of enzymes. Interdisc. Environ. Rev. 3, 14-41.

Parales, R. E., Ditty, J. L. 2005. Laboratory evolution of catabolic enzymes and pathways. Cur. Opin. Biotechnol. 16, 315-325.

Pointing, S. B. 2001. Feasibility of bioremediation by white-rot fungi. Appl. Microbiol. Biotechnol. 57, 20-32.

Raybuck, S. A. 1992. Microbes and microbial enzymes for cyanide degradation. Biodegradation 3, 3-18.

Reddy, C. A. 1995. The potential for white-rot fungi in the treatment of pollutants. Curr. Opin. Biotechnol. 6, 320-328.

Rodríguez Couto, S. 2009. Dye removal by immobilised fungi. Biotechnol. Adv. 27, 227-235.

Rodríguez Couto, S., Toca Herrera, J. L. 2006. Industrial and biotechnological applications of laccases: A review. Biotechnol. Adv. 24, 500513.

Rubilar, O., Diez, M. C., Gianfreda, L. 2008. Transformation of chlorinated phenolic compounds by white rot fungi. Crit. Rev. Environ. Sci. Technol. 38, 227-268.

Sánchez, C. 2009. Lignocellulosic residues: biodegradation and bioconversion by fungi. Biotechnol. Adv. 27, 185-194.

Sheldon, R. A., van Rantwijk, F. 2004. Biocatalysis for sustainable organic synthesis. Austr. J. Chem. 57, 281-289.

Singh, R., Sharma, R., Tewari, N., Geetanjali, Rawat D. S. 2006. Nitrilase and its application as a 'green' catalyst. Chem. Biodiv. 3, 1279-1287.

Singh, C. J. 2002. Optimization of an extra cellular protease of Chrysosporium keratinophilum and its potential in bioremediation of keratinic wastes. Mycopathologia 156, 151156

Solomonson, L. P. 1981. Cyanide as a metabolic inhibitor. In: B., Vannesland, E.E., Conn, C.J., Knowles, J., Westley, F. Wissing (eds), Cyanide in Biology. Academic Press, London, pp: 11-28.

Sornyotha, S., Kyu, K. L., Ratanakhanokchai, K. 2010. An efficient treatment for detoxification process of cassava starch by plant cell walldegrading enzymes. J. Biosci. Bioeng. 109, 9-14.

Sutherland, T., Russel, R., Selleck, M. 2002. Using enzymes to clean pesticide residues. Pestic. Outlook 13, 149-151. 
Torres, E., Bustos-Jaimes, I., Le Borgne, S. 2003. Potential use of oxidative enzymes for the detoxification of organic pollutants. Appl. Catal. B: Environ. 46, 1-15.

Whiteley, C.G., Lee, D.-J. 2006. Enzyme technology and biological remediation. Enzyme Microb. Technol. 38, 291-316.

Zhuang, X., Chen, J., Shim, H., Bai, Z. 2007.

Torres-Duarte, C., Roman, R., Tinoco, R., New advances in plant growth-promoting Vazquez-Duhalt, R. 2009. Halogenated pesticide transformation by a laccase-mediator system. Chemosphere 77, 687-692.

rhizobacteria for bioremediation. Environ. Int. 33, 406-413.

van Wyk, J. P. H. 1999. Saccharification of paper products by cellulase from Penicillium funiculosum and Trichoderma reesei. Biomass Bioener. 16, 239-242. 